\title{
Legislative and Institutional Gaps in the Legal Framework for Adaptation and Mitigation of the Climate Change in the Kyrgyz Republic
}

\author{
Rauf Akhmatov', Cholpon Sulaimanova ${ }^{2}$, Zhyldyz Dekhkanova ${ }^{3}$, Ailira Abdyraimova4, \\ Zhazgul Zheenbekova5 ${ }^{5}$, Edilbek Begaliev5, Zhypargul Abdullaeva6* (D) \\ ${ }^{1}$ Department of Jurisprudence, Kyrgyz Russian Slavic University, Bishkek, Kyrgyzstan \\ ${ }^{2}$ Department of Civil Law and Procedure, Kyrgyz Russian Slavic University, Bishkek, Kyrgyzstan \\ ${ }^{3}$ Department of Theory, Government History and Law, Osh State University, Osh, Kyrgyzstan \\ ${ }^{4}$ Department of Civil Law and Procedure, Osh State University, Osh, Kyrgyzstan \\ ${ }^{5}$ Department of Criminal Law and Procedure, Osh State University, Osh, Kyrgyzstan \\ ${ }^{6}$ Science and Research Department, Osh State University, Osh, Kyrgyzstan \\ Email: *jypar.science@oshsu.kg
}

How to cite this paper: Akhmatov, B., Sulaimanova, C., Dekhkanova, Z., Abdyraimova, A., Zheenbekova, Z., Begaliev, E. and Abdullaeva, Z. (2021). Legislative and Institutional Gaps in the Legal Framework for Adaptation and Mitigation of the Climate Change in the Kyrgyz Republic. Open Journal of Political Science, 11, 357-369. https://doi.org/10.4236/ojps.2021.113024

Received: March 29, 2021

Accepted: May 16, 2021

Published: May 19, 2021

Copyright $\odot 2021$ by author(s) and Scientific Research Publishing Inc. This work is licensed under the Creative Commons Attribution International License (CC BY 4.0).

http://creativecommons.org/licenses/by/4.0/

\begin{abstract}
Climate change is one of the biggest threats and challenges that humankind has ever faced. Therefore, humankind has to convey the earth's climate to future generations at its best by all means necessary. In doing so, the law is the instrument that can create, maintain and develop an adequate mitigation and adaptation framework for climate change. It is important to note that the earth's climate is a common responsibility in the international community and each country has its own obligation concerning climate change. In this sense, authors discuss the international legal framework for climate change influencing legal framework and gaps in the Kyrgyz Republic at the institutional level.
\end{abstract}

\section{Keywords}

Climate Change, Kyrgyz Republic, Commitments, Legislative Gaps, Institutional Gaps, Framework Convention, Kyoto Protocol, Paris Agreement

\section{Introduction}

Ecological protection of Kyrgyzstan, which is located in the runoff formation area of the Aral Sea basin, has a great effect on the downstream and Aral Sea conservation (Hao et al., 2019). Kyrgyzstan territory is affected by the ecological threat of anthropogenic factors, influence on environmental degradation directly 
affecting the scale of the damage (Tynybekov et al., 2008). Climate change is one of the biggest threats that humanity has ever faced. International environmental law principles provide that the Earth's climate system is a common concern (MacKenzie, 2011) that government needs to co-operate to prevent environmental degradation and that promoting a precautionary approach to addressing climate change is of foremost importance (Wiener, 1999). Study of climate change at the global scale is important for regional manifestations of the climate system at spatial scales (Xie et al., 2015). Scientists noted that gases, accumulating mainly from the burning of fossil fuels and forests clearing, add to the natural "greenhouse effect" (Butler, 2018).

Therefore, under the agenda of "Climate Change is a common concern», the United Nations General Assembly launched the development of international agreements regulating climate change by passing resolution 45/212 that became a basis for the United Nations Framework Convention on Climate Change (Gray et al., 2016).

The United Nations Framework Convention on Climate Change as a framework instrument establishes requirements for negotiating and decision making by providing an international platform and gives the direction for climate change regime Change (Gray et al., 2016). Therefore, it is considered as a legal basis for the advancement of the norms and guiding principles of international climate change law (Gray et al., 2016).

The international climate change agreement, which contains binding provisions, is the Kyoto Protocol. It provides legally binding obligations concerning the emission reduction for the developed States, mitigation mechanisms based on carbon trading market, and legally frames the climate regime. The United Nations Framework Convention on Climate Change and Kyoto Protocol is the basis for the current climate change regime. However, the current regime is no longer considered by the international community to be the appropriate basis for the resolution of the climate change issues because major emitters avoid being bound by it and it is unable to respond to the social, political, and economic changes affecting the climate change. Therefore, the problem of the international legal framework for climate change affecting the legal framework in the Kyrgyz Republic is discussed in the Article.

The effects of climate change have been destructive to the environment and ecology of the Kyrgyz Republic and harshly require measures to be reduced. Those measures include the active participation of the State on an international and regional level and cooperation between State bodies, NGOs and civil society. However, the initial step to the effective realization of the aforementioned measures in the Kyrgyz Republic is subject to legal regulation (Center for Climate Change in Kyrgyz Republic, 2021). Mitigation paid attention to energy efficiency, conservation and consistency, and conservation that refers to improving technology in energy use (Gong et al., 2020). Climate change adaptation (De Rose et al., 2018) have been included in the European Structural and Investment Funds approval process (ESIF) contributing to climate proofing projects. 
The article focuses on legal challenges that arise from both international and national legal frameworks for climate change. Since both international and national legal frameworks are mainly based on international agreements, the methodology of the research is based on analysis of the aforementioned international agreement and the current legislation of the Kyrgyz Republic. Even though a lot of research was conducted on the climate change regime, its omission and advantages, there are no Articles, at least known to the author, that would contain comprehensive and adequate analysis of the international legal framework and its consequences on the Kyrgyz Republic and the adequacy of the Kyrgyz Republic's legislation. In this regard, the Article uses the synthesis method by connecting the published researches and providing scrutiny and profound amplification of the issues discussed in the Article.

The Article elaborates on institutional challenges, for instance, a set of governmental bodies of the Kyrgyz Republic that deal with climate change, however, duplicate each other's functions and do not possess adequate powers to implement their own decisions.

For each problem discussed, the Article proposes recommendations for their resolution, such as the creation of the single governmental structure as the Ministry of Environment and the adoption of the law on climate change. The article analyzes the advantages and disadvantages of the suggested solutions and provides recommendations concerning which solution is possibly more appropriate and adequate in terms of the Kyrgyz Republic to fix the discussed problems.

\section{The Commitments of the Kyrgyz Republic under International Agreements}

To analyze the legal framework for climate change regulation in the Kyrgyz Republic, it is important to analyze the international climate change agreements to which the Kyrgyz Republic is party, pros and cons of the obligations that the Kyrgyz Republic has under these agreements and the compliance with these obligations. Junction to United Nations Framework Convention on Climate Change and NFCCC ratification in the Kyrgyz Republic were adopted. Commitments of the Kyrgyz Republic by Kyoto protocol for assistance in preparing the second National Communication obligations with the projects, actions and measures on the capacity building were implemented.

\subsection{Commitments under UNFCCC}

The $20^{\text {th }}$ century gave a rise to discussions concerning international agreements that would deal with mitigation and adaptation of climate change. Thus, in 1990 United Nations General Assembly launched the development of international agreements concerning climate change by passing resolution 45/212 that became a basis for the United Nations Framework Convention on Climate Change (Gray et al., 2016). The United Nations Framework Convention on Climate Change is considered as a legal basis for the advancement of the norms and guiding principles of international climate change law (Gray et al., 2016). The Kyrgyz Repub- 
lic ratified UNFCCC in 2000 (Law of the Kyrgyz Republic on Joining of the Kyrgyz Republic to the UN Framework Convention on Climate Change and the UNECE Convention on Long-Range Transboundary Air Pollution, 2000) and subsequently adopted Resolution 369 on measures required to implement the UNFCCC (Resolution of the Government of the Kyrgyz Republic on Measures to Implement the United Nations Framework Convention on Climate Change, 2001b).

The Kyrgyz Republic is in the Non-Annex I States of the UNFCCC (Ilyasov et al., 2013). Non-Annex I States do not have specific obligations except those stipulated in Article 4.1 of the Convention that requires periodic update and publication of information concerning the climate change situation in the country, implementation of the regional programs, etc (UN General Assembly, United Nations Framework Convention on Climate Change, 1994). Subsequently, the Kyrgyz Republic has conducted the First National Communication of the Kyrgyz Republic submitted in 2004 (Ilyasov et al., 2003).

From the legal standpoint, the law on ratification of the UNFCCC (Law of the Kyrgyz Republic on Joining of the Kyrgyz Republic to the UN Framework Convention on Climate Change and the UNECE Convention on Long-Range Transboundary Air Pollution, 2000), and the Resolution 369 of the Kyrgyz Republic Government on measures required to implement the UNFCCC were the only commitments undertaken by the government of the Kyrgyz Republic (Resolution of the Government of the Kyrgyz Republic on Measures to Implement the United Nations Framework Convention on Climate Change, 2001b).

\subsection{Commitments under Kyoto Protocol}

In January 2003, the government of the Kyrgyz Republic ratified the Kyoto Protocol (Law of the Kyrgyz Republic on Ratification of the Kyoto Protocol to the United Nations Framework Convention on Climate Change, 2003). The Kyoto protocol displaces obligations mainly on Annex I and Annex II parties of the UNFCCC (Gray et al., 2016). The obligation stipulated in the Kyoto protocol for non-Annex parties is a reaffirmation of the obligations stipulated in UNFCCC article 4.1. Consequently, article 10 of the Kyoto Protocol requires all parties to formulate the cost-effective regional programs, preparation and periodic updating of national inventories, etc. (Gray et al., 2016).

The commitments of the Kyrgyz Republic under the Kyoto protocol include the creation of the "Assistance to the Kyrgyz Republic in preparing the second National Communication in response to obligations to the UNFCCC 19 project, which was carried out from 2005 to 2008 . The project helped to strengthen technical and institutional capacity to integrate climate change issues into the countries' sectoral and national development priorities (Ilyasov \& Yakimov, 2009).

The Resolution of the Government of the Kyrgyz Republic dated November 21, 2012, No. 783 established the Coordination Commission on Climate Change chaired by the Vice Deputy Minister of the Kyrgyz Republic responsible for environmental issues (Resolution of the Government of the Kyrgyz Republic on 
the Coordination Commission on Climate Change Issues, 2012c) The main purpose of the Coordination Commission is to lead and coordinate the activities of ministries, departments and organizations in fulfilling the obligations of the Kyrgyz Republic under the UNFCCC and the Kyoto Protocol. As a result of such establishment several laws such as law "On the State Regulation and Policy of Greenhouse Gas Emission and Absorption" dated 25 May 2007, law "On the State Regulation and Policy of Greenhouse Gas Emissions and Absorption" and "Environmental Security Concept of the Kyrgyz Republic" were adopted and amendments were introduced into the laws "On Environment Protection" (Law on Environment Protection, 1999) and "On Protection of Atmospheric Air" (Law on Air Protection, 1999) and "Strategy and Action Plan for National Capacity Building to Implement the Global Environmental Conventions" (Strategy and Action Plan for National Capacity Building to Implement the Global Environmental Conventions, 2007). From a legal standpoint, the commitments under the Kyoto Protocol and the period of second national communication are considered the most conducive ones.

\subsection{Commitments under the Paris Agreement}

There is no binding obligation stipulated in the Paris Agreement upon developing parties except those stipulated in Articles 4.8 and 11.4 that are to submit Nationally Determined Contributions and regularly communicate on actions and measures on capacity building respectively (Paris Agreement to the United Nations Framework Convention on Climate Change, 2015). Therefore, being a developing party to the agreement the Kyrgyz Republic does not have any significant obligations under the Paris Agreement.

\section{Challenges and Legislative Gaps in the Legal Framework for Climate Change Regulation in the Kyrgyz Republic}

Climate change is a subject of legal regulation in the first place. The legislation of the Kyrgyz Republic insufficiently deals with climate change issues. Namely, the contradictions within the obligations and the powers of the institutions regulating climate change and legislative gaps are the main obstacles when considering the legal framework for climate change regulation. Institutional challenges are regulating climate change in the Kyrgyz Republic by the State Agency for Environmental Protection and Forestry under the Government of the Kyrgyz Republic, Climate Change Center in the Kyrgyz Republic and Climate Finance Center in the Kyrgyz Republic, while legislative gaps are based on the government regulation and policies on the emission and absorption of greenhouse gases and provide a unique mechanism of mitigation in climate change.

\subsection{Institutional Challenges in the Legal Framework for Climate Change Regulation in the Kyrgyz Republic}

Currently, there are three institutions regulating climate change in the Kyrgyz Republic. These are The State Agency for Environmental Protection and Fore- 
stry under the Government of the Kyrgyz Republic (hereinafter State Agency); Climate Change Centre in the Kyrgyz Republic and Climate Finance Center of the Kyrgyz Republic. All of these institutions deal with climate change and were established by the government of the Kyrgyz Republic. Their responsibilities mostly coincide at the functional level. Therefore, it is important to scrutinize the purpose of the creation, functions, rights as well as goals of these institutions to evaluate their profitability to the present climate change regulation regime of the Kyrgyz Republic.

The State Agency was established in 2012, by the Resolution of the Government of the Kyrgyz Republic (Resolution of the Government of the Kyrgyz Republic, 2008). It is an executive body for the implementation of policies and regulation of relations in the field of environmental protection, environmental safety and environmental management (Resolution of the Government of the Kyrgyz Republic, 2008). In the initial stages of its operation, the State Agency was responsible for the establishment of the following bodies: local funds for nature conservation and forestry development; Center for state regulation in the field of environmental protection and environmental safety and the Department of forest management (Resolution of the Government of the Kyrgyz Republic, 2008). However, very little is said about its functions towards climate change. The only mentioning of climate change regulation in the State of State Agency is given through the following wording “... coordinates the protection of atmospheric air, production and consumption of ozone-depleting substances, use and protection of water resources in terms of climate change...".

The comparative analysis of the State Agency, Climate Change Coordination Committee and the Center for Climate Finance of the Kyrgyz Republic showed that the functions and organizational structure of these institutions duplicate each other. Although they have differences, the balance of power seems to be inclined based on the financial benefits that institutions can bring. For instance, all of the institutions mentioned above are obliged to promote and maintain international cooperation in the field of environmental protection. For instance, article 5 of the Regulation on the State Agency provides the establishment and development of international cooperation of the Kyrgyz Republic in the field of environmental protection, environmental safety and environmental management (Resolution of the Government of the Kyrgyz Republic, 2008). So does article 9 on the Regulation on Climate Finance Centre (Resolution of the Government of the Kyrgyz Republic, 2017).

The State Agency and the Climate Change Coordination Committee, for instance, share almost the same functions in terms of air protection, production and consumption of ozone-depleting substances, use and protection of water resources influenced by climate change (Resolution of the Government of the Kyrgyz Republic, 2008). All of the above-mentioned institutions share functions on organizing, jointly with the interested state bodies and scientific institutions, the development of proposals for implementing the policy and development of regional programs for environmental protection and environmental manage- 
ment (Resolution of the Government of the Kyrgyz Republic, 2008). In addition, they share functions on organizing scientific, technical, expert and other councils, groups and commissions for conducting expertizes and other related procedures (Resolution of the Government of the Kyrgyz Republic, 2008). They do share functions on ensuring coordination in "full, open and operational exchange of scientific, technological, technical, socio economic" and legal information and assistance in organizing events in the field of education, training and public awareness on environmental issues (Resolution of the Government of the Kyrgyz Republic on the Coordination Commission on Climate Change Issues, 2012c). All of the aforementioned institutions are responsible for attracting money for climate projects and environmental projects (Resolution of the Government of the Kyrgyz Republic, 2008).

Both the State Agency and Climate Finance Centre are responsible for financing environmental protection measures and have a right to make proposals to the Government of the Kyrgyz Republic (Resolution of the Government of the Kyrgyz Republic on the Coordination Commission on Climate Change, 2012c). There are a few differences between these institutions except those that are stipulated as objectives of the institutions. The State Agency is responsible for ensuring the preservation of a unique ecological system; (Resolution of the Government of the Kyrgyz Republic, 2008) the Climate Change Coordination Committee is responsible for directing and coordinating the activities of ministries, departments and organizations to fulfill the commitments of the Kyrgyz Republic under the UNFCCC and the Kyoto Protocol (Resolution of the Government of the Kyrgyz Republic, 2012c) and the Climate Finance Centre is responsible for assistance in attracting financial resources and investments (Resolution of the Government of the Kyrgyz Republic, 2017).

However, there are a few other functional differences that only some institutions possess. For instance, only the decisions taken by the Coordination Committee are of a binding nature (Resolution of the Government of the Kyrgyz Republic on the Coordination Commission on Climate Change Issues, 2012c). Another difference lies in the status of the employees of the Climate Finance Centre. They are not considered as government officials and therefore, do not receive any finance from the budget, however, the director of the Centre is appointed by the Prime Minister of the Kyrgyz Republic (Resolution of the Government of the Kyrgyz Republic, 2017).

\subsection{Legislative Gaps in the Legal Framework for Climate Change Regulation in the Kyrgyz Republic}

The government of the Kyrgyz Republic identified the reduction of the greenhouse gases as one of the priority mitigation measures and therefore, has introduced several legal acts such as the decree of the Government of the Kyrgyz Republic "On measures to implement the UN FCCC" and the law of the Kyrgyz Republic "On state regulation and policies on the emission and absorption of greenhouse gases" (The Law of the Kyrgyz Republic, 2007). The law of the Kyr- 
gyz Republic "On state regulation and policies on the emission and absorption of greenhouse gases", provides a unique mechanism of mitigation of climate change such as the State cadaster of emissions and absorption of greenhouse gases (The Law of the Kyrgyz Republic, 2007). Following the aforementioned law, the state cadaster of greenhouse gases emissions and removals is a list of objects of emission and absorption of greenhouse gases with an indication of the levels of emission and absorption of greenhouse gases, reflected in the time dynamics of emission and absorption of greenhouse gases (The Law of the Kyrgyz Republic, 2007). Unfortunately, there is no such cadaster. Moreover, the authorized governmental body responsible for the maintenance of the cadaster is the State Agency (The Law of the Kyrgyz Republic, 2007). However, the regulation on the State Agency does not provide for such obligation. Consequently, the absence of an authorized body and the absence of the cadaster makes it impossible to regulate the emission and absorption of greenhouse gases in the Kyrgyz Republic.

Another major gap could be found in Article 8 of the aforementioned law, which provides that entities, which produce greenhouse gases on the territory of the Kyrgyz Republic, have to have sufficient maximum allowable emissions (quotas) to cover actual emissions of greenhouse gases (The Law of the Kyrgyz Republic, 2007). Quota is the allowed level of greenhouse gas emissions, which has a validity period during which the quota holder has the right to make the appropriate amount of greenhouse gas emissions (The Law of the Kyrgyz Republic, 2007). In the first year after the entry into force of the aforementioned law, and inventory had to be made and the base level of greenhouse gas emissions for the base year had to be identified, and the quota (standard) of greenhouse gas emissions for the next reporting period for each subject of greenhouse gas emissions supposed to be designed by State Agency (The Law of the Kyrgyz Republic, 2007). Unfortunately, all of these measures were not carried out (The Law of the Kyrgyz Republic, 2007).

The law provides that if the emission level exceeds given a quota for the reporting period, the emitter has to purchase quotas for the missing amount of the emissions from a specially authorized government agency or on the greenhouse gas emission market (The Law of the Kyrgyz Republic, 2007). Consequently, the absence of quotas established by law adversely affects the entire quota turnover market, and this, in turn, could have been an additional source of finance for the budget of the Kyrgyz Republic (The Law of the Kyrgyz Republic, 2007). Moreover, the price for quotas still has not been determined. Following the law, the price of quotas acquired from the government set by the Government of the Kyrgyz Republic is based on the proposal of a specially authorized state body. However, a specially authorized state body, until today, has not made any proposals for determining the price of emission quotas.

As it was already stated, most of the above mentioned institutions functions are similar. If we are to analyze the background of environmental regulation in Kyrgyzstan, the government used to have Ministry of Environment (Resolution 
of the Government of the Kyrgyz Republic, 1996) until it was diluted in 1998 and the Ministry of Ecology and Emergency Situations of the Kyrgyz Republic until it was diluted in 2003 and both of the institutions possessed merely same functions except those that were provided under emergency situations (Resolution of the Government of the Kyrgyz Republic, 2001a). Then, the government decided to divide the functions of the Ministry between various agencies and departments. For instance, the State Inspectorate on Environmental and Technical Security received the function of government supervision and control on environmental and technical safety issues (Resolution of the Government of the Kyrgyz Republic, 2012b). As time had shown, such division of the powers led to a deterioration of environmental protection. For instance, when the Ministry of Ecology and Emergency Situations of the Kyrgyz Republic functioned, several normative legal acts were adopted and implemented. These include Regulation on Freelance Public Environmental Inspectors (Regulation on Freelance Public Security Inspectors, 2005); Instructive and methodological instructions on the determination of pollution charges in the Kyrgyz Republic (Resolution of the Government of the Kyrgyz Republic, 2003a); Provisions on the procedure for issuing permits for the operation of hazardous production facilities (Resolution of the Government of the Kyrgyz Republic, 2003b); the Aviation Department at the Ministry of Ecology and emergency situations of the Kyrgyz Republic (Resolution of the Government of the Kyrgyz Republic, 2002), etc. Because aforementioned institutions are mostly coinciding with the functional level and decisions, proposals that they make are non-binding; it seems to be more efficient to have one body regulating environmental protection rather than separating powers and finance between different agencies and departments that most of the times do not have sufficient legal power and finance to efficiently implement their decisions. If we are to analyze the functional scope of the State Agency, it becomes obvious that it resembles the functional scope of other ministries and not agencies. For instance, the functional scope of the Ministry of Economy of the Kyrgyz Republic includes sectoral policy functions, regulatory functions, coordination, control, monitoring functions, service functions and support functions (Resolution of the Government of the Kyrgyz Republic, 2012a). So does the State Agency. Another example, the functions of the Ministry of Agriculture, Food Industry and Land Reclamation include the same scope (Resolution of the Government of the Kyrgyz Republic, 2016; Food and Agriculture Organization of the United Nations, 2021). However, when it comes to the rights of the State Agency, they are quite limited in a legal sense. If we compare the rights provided to the Ministry of Economy or Ministry of Agriculture, they are evidently broader. The question is why the functions and responsibilities of the State Agency and the Ministries are similar but the rights of the State Agency are limited. Therefore, author to provides, that that it be of a vital importance to upgrade the legal status of the State Agency to the Ministry. Moreover, from the legal acts in force, it is not clear who carries out environmental policy and development of it. The 
Law on the Environment of the Kyrgyz Republic, Article 41, designates the Republican State Environmental Protection body of the Kyrgyz Republic as responsible for pursuing a unified state policy. However, nothing mentioned about the development of environmental policy. Given the fact that the Regulation of the State Agency does not provide the State Agency with the right to develop a unified government policy, it does not seem possible to determine the state body responsible for the policy in this area.

However, the Regulation on State Control over the Protection of the Environment, Part II Article 4 sheds clarity on this issue. The above article defines the authority responsible for determining policy in this area, as the Ministry of Environmental Protection of the Kyrgyz Republic, the authority that is no longer exists. This, in turn, proves once again the need for reforming the state agency to the Ministry of Environmental Protection. Summarizing climate change and regulation challenges with gaps, it can be said that the authority, which shall regulate climate change, is not power to do so, because the legislative gaps are given in their regulations. Agriculture sector can play important role in climate change mitigation by reducing emissions, but the sector will also have to take major steps to adapt to a changing climate.

\section{Conclusion}

It is obvious that climate change is inevitable and it is very disappointing that it is not considered as such by the government of the Kyrgyz Republic. The government has created different authorities, designated them to deal with the particular climate change issues, however, when it comes to giving legal power to those entities government abstains from doing so. The functions that could normally be exercised by one authority are being divided into three bodies. Legally speaking, none of these authorities can effectively deal with climate change. After analyzing the main laws and regulations of greenhouse gas emissions, the author concludes that today, thanks to the developed target programs and individual regional regulations, a certain concept of legal regulation of the considered area has emerged. On the other hand, the lack of comprehensive legislative regulation, legislation does not allow us to fully begin to address the problems associated with reducing greenhouse gas emissions.

To create an appropriate accounting system for greenhouse gas emissions, it is advisable to supplement the mentioned law with a separate article on the procedure of maintenance of the state cadaster of emissions, set an accounting system for it, and introduce provisions regarding the obligation of the State Agency to maintain the inventory. In addition, it is necessary to supplement the Regulation of the State Agency with provisions on the conduct of the emission cadaster, the emission accounting system and provide State Agency with the right to request information about ongoing turnover of quotas.

The Article concludes with a recommendation to pay more attention to the question of institutional support for the mitigation and adaptation of climate 
change and take adequate measures to fix the existing legislative gaps to eliminate uncertainty and improve the ecological situation in the Kyrgyz Republic.

\section{Conflicts of Interest}

The authors declare no conflicts of interest regarding the publication of this paper.

\section{References}

Butler, C. D. (2018). Climate Change, Health and Existential Risks to Civilization: A Comprehensive Review (1989-2013). International Journal of Environmental Research and Public Health, 15, 2266. https://doi.org/10.3390/ijerph15102266

Center for Climate Change in Kyrgyz Republic (2021). Kyrgyzstan and the Climate Change. http://climatechange.kg/ky-rgy-zstan-i-izmenenie-klimata/

De Rose, A., Anagnostopoulos, F., Tricot, A., Sandhu, N., Laureysens, I., Vertriest, L., Lammerant, J., \& Adriaenssens, V. (2018). Climate Change Adaptation of Major Infrastructure Projects. A Stock-Taking of Available Resources to Assist the Development of Climate Resilient Infrastructure (p. 143). Brussels: European Commission.

Food and Agriculture Organization of the United Nations (2021). Climate Tech in Kazakhstan and Kyrgyzstan Can Help Stifle Greenhouse Gases. http://www.fao.org/europe/news/detail-news/en/c/1175650/

Gong, X., Liu, Y., \& Sun, T. (2020). Evaluating Climate Change Governance Using the "Polity-Policy-Politics" Framework: A Comparative Study of China and the United States. Sustainability, 12, 6403. https://doi.org/10.3390/su12166403

Gray, K. R., Tarasofsky, R., \& Carlarne, C. (2016). International Climate Change Law: Mapping the Field. In K. R. Gray, R. Tarasofsky, \& C. Carlarne (Eds.), The Oxford Handbook of International Climate Change Law. Oxford: Oxford University Press. https://doi.org/10.1093/law/9780199684601.001.0001

Hao, Y., Yang, D., Yin, J., Chen, X., Bao, A., Wu, M., \& Zhang, X. (2019). The Effects of Ecological Policy of Kyrgyzstan Based on Data Envelope Analysis. Sustainability, 11, 1922. https://doi.org/10.3390/su11071922

Ilyasov, S., \& Yakimov, V. (2009). Second National Communication of the Kyrgyz Republic under the UN Framework Convention on Climate Change.

Ilyasov, S., Podrezov, O. A., \& Rodina, E.M. (2003). First National Communication of the Kyrgyz Republic under the UN Framework Convention on Climate Change.

Ilyasov, S., Zabenko, O., Gaydamak, N., Kirilenko, A., Myrsaliev, N., Shevchenko, V., \& Penkina, L. (2013). The United Nations Development Programme Climate Profile of the Kyrgyz Republic.

Law of the Kyrgyz Republic on Joining of the Kyrgyz Republic to the UN Framework Convention on Climate Change and the UNECE Convention on Long-Range Transboundary Air Pollution (2000). Parliament of the Kyrgyz Republic. May 20, No. 121.

Law of the Kyrgyz Republic on Ratification of the Kyoto Protocol to the United Nations Framework Convention on Climate Change (2003). Republican Newspaper "Erkin-Too". January 15, No. 9.

Law on Air Protection (1999). Republican Newspaper “Erkin-Too”. June 12, No. 51.

Law on Environment Protection (1999). Republican Newspaper "Erkin-Too". June 16, No. 53.

MacKenzie, C. (2011). Fairness in International Climate Change Law and Policy. By 
Friedrich Soltau. [Cambridge: Cambridge University Press, 2009. 304 pp. Hardback £59. ISBN 9780521111089.]. The Cambridge Law Journal, 70, 472-475. https://doi.org/10.1017/S0008197311000602

Paris Agreement to the United Nations Framework Convention on Climate Change (2015). Article 2. Paris: UN.

Resolution of the Government of the Kyrgyz Republic (1996). The Ministry of the Environment Kyrgyz Republic. September 26, No. 443.

Resolution of the Government of the Kyrgyz Republic (2001a). The Ministry of Ecology and Emergency Situations of the Kyrgyz Republic. February 24, No. 59.

Resolution of the Government of the Kyrgyz Republic on Measures to Implement the United Nations Framework Convention on Climate Change (2001b). Government House. July 23, No. 369.

Resolution of the Government of the Kyrgyz Republic (2002). The Aviation Department under the Ministry of Ecology and Emergencies of the Kyrgyz Republic. December 12, No. 848.

Resolution of the Government of the Kyrgyz Republic (2003a). On Approval of Instructional Guidelines for Determining Charges for Environmental Pollution in the Kyrgyz Republic. July 1, No. 401.

Resolution of the Government of the Kyrgyz Republic (2003b). Provisions on the Procedure for Issuing Permits for the Operation of Hazardous Production Facilities. June 11, No. 242.

Regulation on Freelance Public Security Inspectors (2005). April 6, No. 168.

Resolution of the Government of the Kyrgyz Republic (2008). The State Agency for Environmental Protection and Forestry under the Government of the Kyrgyz Republic. April 10, No. 139.

Resolution of the Government of the Kyrgyz Republic (2012a). Ministry of Economy of the Kyrgyz Republic. February 20, No. 117.

Resolution of the Government of the Kyrgyz Republic (2012b). About the State Inspectorate for Environmental and Technical Security under the Government of the Kyrgyz Republic. February 20, No. 136.

Resolution of the Government of the Kyrgyz Republic on the Coordination Commission on Climate Change Issues (2012c). Republican Newspaper "Erkin-Too”. December 23, No. 783.

Resolution of the Government of the Kyrgyz Republic (2016). On "the Ministry of Agriculture, Food Industry and Land Reclamation of the Kyrgyz Republic". Dated of November 11, 2016, No. 576.

Resolution of the Government of the Kyrgyz Republic (2017). The State Agency for Environmental Protection and Forestry under the Government of the Kyrgyz Republic. Establishment of the Center for Climate Finance of the Kyrgyz Republic, August 14, No. 478 .

Strategy and Action Plan for National Capacity Building to Implement the Global Environmental Conventions (2007). Republican Newspaper "Erkin-Too". July 23, No. 521.

The law of the Kyrgyz Republic (2007). On State Regulation and Policies on the Emission and Absorption of Greenhouse Gases. May 25, No. 71.

Tynybekov, A. K., Lelevkin, V. M., \& Kulenbekov, J. E. (2008). Environmental Change and Human Security. In P. H. Liotta, D. A. Mouat, W. G. Kepner, \& J. M. Lancaster (Eds.), Environmental Change and Human Security: Recognizing and Acting on Hazard Impacts. NATO Science for Peace and Security Series C: Environmental Security 
(pp. 407-432). Dordrecht: Springer. https://doi.org/10.1007/978-1-4020-8551-2 18

Wiener, J. B. (1999). Global Environmental Regulation: Instrument Choice in Legal Context. The Yale Law Journal, 108, 677-800. https://doi.org/10.2307/797394

Xie, L., Semazzi, F., Hanna, A., Richard, A., Gao, H., \& He, Y. (2015). Regional Climate Change: Downscaling, Prediction, and Impact Assessment. Advances in Meteorology, 2015, Article ID: 290281. https://doi.org/10.1155/2015/290281 